\title{
When are readership counts as useful as citation counts? Scopus vs. Mendeley for LIS Journals ${ }^{1}$
}

Nabeil Maflahi, Mike Thelwall. Statistical Cybermetrics Research Group, School of Mathematics and Computer Science, University of Wolverhampton, Wulfruna Street, Wolverhampton WV1 1LY, UK

In theory, articles can attract readers in the social reference sharing site Mendeley before they can attract citations and so Mendeley altmetrics could provide early indications of article impact. This article investigates the influence of time on the number of Mendeley readers of an article through a theoretical discussion and an investigation into the relationship between counts of readers of, and citations to, four general Library and Information Science (LIS) journals. For this discipline, it takes about seven years for articles to attract as many Scopus citations as Mendeley readers and after this the Spearman correlation between readers and citers is stable at about $\mathbf{0 . 6}$ for all years. This suggests that Mendeley readership counts may be useful impact indicators for both newer and older articles. The lack of dates for individual Mendeley article readers and an unknown bias towards more recent articles mean that readership data should be normalised individually by year, however, before making any comparisons between articles published in different years.

\section{Introduction}

Altmetrics, indicators of interest in academic publications created from social web mentions (Priem, Taraborelli, Groth, \& Neylon, 2010), were increasingly used by publishers in early 2014, including Elsevier (Scopus reports the number of Mendeley readers for articles), PLoS (reports a suite of article-level metrics, including CiteULike and Mendeley readers, tweets, comments and Wikipedia citations) and the Nature Publishing Group (a range of "attention" metrics from altmetric.com, including tweets, and Facebook, blog and news mentions). Suites of altmetrics for articles are provided by at least three separate organisations: ImpactStory.org, Altmetric.com (Adie \& Roe, 2013) and Plum Analytics. A range of metrics can be informative for readers, especially if similar altmetrics are grouped together (Lin \& Fenner, 2013). In particular, article-level metrics can reveal the interest that other researchers have shown in articles, flagging them as potentially important to read (Priem, Taraborelli, Groth, \& Neylon, 2010), a kind of simple collaborative filtering (Breese, Heckerman, \& Kadie, 1998). In general, moreover, the more an article is mentioned in the social web, the more likely it is to be cited (Li, Thelwall, \& Giustini, 2012; Thelwall, Haustein, Larivière, \& Sugimoto, 2013; Zahedi, Costas, \& Wouters, in press).

Although altmetrics are used by publishers to give readers additional metadata about articles, some altmetrics can also be used to investigate the science system itself. Examples include tracking knowledge flows between disciplines (Mohammadi \& Thelwall, in press), identifying international readership patterns (Thelwall \& Maflahi, in press), and investigating which types of people read research articles (Mohammadi, Thelwall, Haustein, \& Larivière, in press; Zahedi, Costas, \& Wouters, 2013). Altmetrics can also be used to investigate how academics use the social web to publicise their new findings (Bar-llan, Haustein, Peters, et al., 2012; Holmberg, \& Thelwall, in press) or to discuss research (Peters, Beutelspacher, Maghferat, \& Terliesner, 2012; Weller, Dröge \& Puschmann, 2011), as well as how other scientists (Priem \& Costello, 2010; Shuai, Pepe, \& Bollen, 2012; Thelwall, Tsou, Weingart, Holmberg, \& Haustein, 2013) or the public (Allen, Stanton, Di Pietro, \& Moseley,

\footnotetext{
${ }^{1}$ This is a preprint of an article to be published in the Journal of the Association for Information Science and Technology @ copyright 2014 John Wiley \& Sons, Inc.
} 
2013) react to new research. In addition, altmetrics can be used to predict future scholarly citations in some contexts in the case of tweets (Eysenbach, 2011) and blog posts (Shema, Bar-llan, \& Thelwall, in press). In general, however, the use of altmetrics to predict citations is problematic because many articles have zero altmetric scores (Costas, Zahedi, \& Wouters, 2014; see also: Haustein, Peters, Bar-llan et al., in press), altmetrics have only a low correlation or relationship with citations (Costas, Zahedi, \& Wouters, 2014; Haustein, Peters, Sugimoto, et al., 2014; Thelwall et al., 2013; Waltman \& Costas, 2013) and it is not reasonable to compare altmetrics for articles published at different times (Thelwall et al., 2013).

Finally, and perhaps most controversially, altmetrics have been proposed for evaluative purposes, for example through listing key values on a scholar's CV (Piwowar \& Priem, 2013). Altmetrics have also been claimed to have the potential aid the decisionmaking of institutions if they can be provided in aggregate format, for example to give departmental average scores (Roemer \& Borchardt, 2013), but such uses would need extensive testing to assess whether they are justifiable. Altmetrics have the advantages of being available before citations, recognising a wider audience than just publishing scholars, and perhaps overcoming to some extent the national coverage biases of traditional citation indexes (Alperin, 2013) and so it seems worthwhile to investigate and evaluate their potential further. Nevertheless, evaluative uses of altmetrics are seen as a particular threat by some scientists due to concerns that they (e.g., tweet counts) will trivialise research (Colquhoun \& Plested, 2014), which is something that should be guarded against. Moreover, altmetrics are rarely peer-reviewed and are therefore vulnerable to gaming (Beall, 2012) and so should not be used for important evaluations unless they can "adhere to a far stricter protocol of data quality and indicator reliability and validity" (Wouters \& Costas, 2014) than that which would be adequate for publishers' article-level metrics. An exception is perhaps when the academic themselves opts to use altmetrics as evidence to support a case for an activity of theirs (e.g., blogging) having had an impact outside of scholarly publishing (ACUMEN, 2014).

For all of the above applications, it is important to assess the reliability of the information that altmetrics apparently give (Sud \& Thelwall, 2014). One important limitation is temporal, which is the primary issue in the current article. Time is a problem for altmetrics because the web services that they are based upon are relatively new and can have expanding user-bases. This can lead to counter-intuitive results such as negative correlations between tweets and citations for articles published at different times, even within the same year (Thelwall, Haustein, Larivière, \& Sugimoto, 2013). This can be caused by citations taking time to accumulate and hence tending to be higher, on average, for older articles, whereas social web users may focus primarily on the most recent articles. Thus, if the number of social web users is increasing then newer articles can tend to have, on average, higher altmetric scores than older articles, reflecting the expanding user base.

Mendeley seems to be a particularly important source of altmetrics because $63 \%$ of Web of Science articles from 2005 to 2011 had at least one Mendeley reader by April 2013 (Zahedi, Costas, \& Wouters, in press) and because readership seems intuitively to be a good indicator of impact in comparison to other social web activities, such as tweeting. This article addresses the following questions in order to shed more light on the importance of time for Mendeley readership statistics. The second research question concerns only one discipline, LIS, so that an in-depth investigation of the results is possible.

- Which time-related factors are likely to influence how Mendeley reader counts should be interpreted? This is addressed with a theoretical discussion in the next section. 
- How does the relationship between Mendeley readership counts and citations vary over time? This is answered for Scopus citations to four core general LIS journals.

\section{The role of time in citing and reading articles}

In general, an article may start to have an impact when other researchers first read it and at some stage in the future its impact may peak and then start to decline, eventually finishing when it is no longer read - although it is never certain that an article will be ignored in the future because some articles only attract attention after a substantial period of time (van Raan, 2004). Scholars tend to read current articles more often than older articles, perhaps as part of their strategy for keeping up-to-date (Tenopir, Volentine, \& King, 2012). The cited half-life of an article, which is the number of years taken for it to attract $50 \%$ of its eventual number of citations (Amin \& Mabe, 2000), is a calculation based upon the assumption of an eventual decline in the rate of attracting new citations. Below are factors that seem intuitively likely to affect the lifecycle of articles, some of which apply differently to Mendeley readership and citation counting. These factors affect scholars to different extents because their information seeking behaviour styles vary significantly (Palmer, 1991). Moreover, these factors may change in importance over time due to technological factors. For example, electronic availability seems to have prompted more reading of older articles by US science faculty (Tenopir, King, Edwards, \& Wu, 2009).

- Researching and writing delays (mainly affects citers). Although an article may be registered in Mendeley on the day that it is first found (perhaps being reading later), it may take considerably longer for a citation to the article to appear in a finished write-up (e.g., an article submitted for publication). For example, if the paper is found during a literature review at the start of a $\mathrm{PhD}$ then there may be a delay of at least three years until the $\mathrm{PhD}$ thesis is complete, although a paper may also be completed on the same day if the reference is found during final literature checks. There do not seem to be any studies of the delay between reading and citing articles but it seems likely to take months or years. In contrast, articles may be registered in Mendeley in advance of reading by those keeping track of useful results (Pautasso, 2013), although references could also be recorded long after reading (e.g., after the literature review, when writing the reference list).

- Publishing delays (only affects citers). There is typically a delay of between 9 and 18 months from the first submission of an article to an academic journal until its final publication, depending upon discipline, with sciences tending to be faster and the delay for the social sciences being about 14 months (Björk \& Solomon, 2013). Citations may appear in citation indexes before the article is officially published if early versions are available, however, and preprints may also be indexed in Google Scholar.

- Enhanced impact at publication time as articles are promoted by current awareness services and found by browsing current issues. Current awareness services (Barr, 2006) include newsletters, email/Twitter/RSS alerts from publishers and libraries. They seem to be used by a substantial minority of academics (Niu, Hemminger, Lown, et al., 2010) although they rarely seem to lead to articles to read (Niu et al., 2010; Tenopir et al., 2012). Current awareness also includes more informal channels, such as acquaintances tweeting or talking about their just-published articles, and browsing the latest issues of selected journals (e.g., Vakkari \& Talja, 2006). 
- Sustained or increasing impact over time for cited articles. Cited articles can attract new readers who follow references in the citing articles (snowballing or citation chaining: Talja, Vakkari, Fry, \& Wouters, 2007) or who find the cited article more easily in databases like Google Scholar that use citations to rank articles or that display citation counts for articles (e.g., $15 \%$ of articles read by US researchers in 2005 came from citations: Tenopir et al., 2009).

- Sustained impact due to educators recommending articles to students (mainly affects readers). Course reading lists generate new student readers of articles but probably few formal citations from them. Reading lists may contain more standard works and textbooks for lower level courses but may be more varied and challenging for higher level courses (Stokes \& Martin, 2008), and so, in general, reading lists probably serve to give sustained readership impact for classic works (especially because students tend to focus on the latter: Stokes \& Martin, 2008). For reading lists that include current research, there may still be a delay if the reading list is compiled in advance of the course. Reading lists are sometimes unchanged or only slightly updated each year (e.g., Brewerton, 2014), and this would generate extra student readers for an article for several years after it was first added to a reading list.

- Obsolescence (may affect readers less than citers). Articles that are replaced by future similar research would presumably attract less interest. Fashionable research topics that fall out of favour would also have a reduced audience. Topics may also become obsolete, for example if the technology investigated ceases to be used much (e.g., Gopher). Moreover, literature searches following the guideline, "be up-to-date, but do not forget older studies" (Pautasso, 2013) would search more exhaustively for newer papers. These issues all contribute to the recognised problem of literature obsolescence (e.g., Line \& Sandison, 1974). This may affect students (and hence readers, on average) less than researchers since the latter need to be up-to-date to publish whereas lecturers sometimes teach old fashioned material (e.g., Sulaiman, Ahmad, \& Alwi, 2005). Classic, highly cited articles may be an exception, however (e.g., Case \& Higgins, 2000).

The above list is unlikely to be exhaustive and other factors are likely to be identified in the future. For example, authors often learn about papers from personal contacts (Tenopir et al., 2009) but it is unclear whether this might lead to publication delays through, for example, senior researchers advising junior researchers about important papers from their youth.

The apparent time difference between reading or finding an article and citing it is an important advantage of Mendeley altmetrics, although concrete evidence is needed to confirm that Mendeley users typically add articles to their libraries at about the time that they find or read them. Nevertheless, there are also sources of delay or sustained interest that are more relevant to student readers than to publishing readers/citers (e.g., course reading lists). As a result, patterns of citing articles do not necessarily lag behind patterns of reading the same articles. For example, it is plausible that the readership half-life of many articles would be longer than their citation half-life because they continue to be on syllabuses after they have ceased to be relevant for current research.

Finally, an important time-related technical limitation of Mendeley that citation indexes do not have is that it is not possible to determine the date at which an article was read because Mendeley only reports the total number of readers and does not break down the pattern of readership by year. This makes it impossible to normalise readership statistics in any way analogous to the use of citation windows for citation analysis purposes. To 
compare different years, readership statistics would have to be normalised in some other way, such as against other articles from the same year. A natural method would be to report the top percentile for an article in its year (e.g., in the top $15 \%$ for the year) although this would give an advantage to articles published earlier in the year.

\section{Methods}

LIS academics publish in a wide variety of LIS journals as well as in conferences, monographs, edited volumes, professional magazines and other fields' journals. This article focuses on the core type of publication, LIS journal articles, and citations in one database, Scopus. Scopus was chosen because it seems to have more extensive coverage than the Web of Science, at least for recent articles. For example, Scopus has $40 \%$ higher coverage for Iranian-authored publications 1998-2007 (Erfanmanesh \& Didegah, 2013), had greater coverage of clinical medicine and nursing in 2013 (Li, Burnham, Lemley, \& Britton, 2010), and also had greater coverage for soil scientists in 2013 (Minasny, Hartemink, McBratney, \& Jang, 2013). Whilst it would have been possible to check all articles in the Scopus LIS category (3309), it does not fit the LIS discipline well (Abrizah, Zainab, Kiran, \& Raj, 2013), for example by excluding the Journal of the American Society for Information Science and Technology for some years and including some mathematical, telecommunications and music journals. Hence, instead of including the full Scopus category, four key general LIS journals were selected: Information Processing \& Management (IPM), Library and Information Science Research (LISR), the Journal of Documentation (JDoc) and the Journal of the American Society for Information Science and Technology (JASIST), which was formerly the Journal of the American Society for Information Science (JASIS) and which is currently the Journal of the Association for Information Science and Technology. This restriction to four journals allows a more narrow focus on core LIS research, although JASIST is a generalist journal and hence contains non-LIS research that is relevant to LIS. Also, IPM seems to have recently changed into a computer science journal.

The four LIS journals were searched for in Scopus on April 6, 2014 by name (using SRCTITLE) and year, with the earlier form of JASIST's name used (Journal of the American Society for Information Science), which matches both the earlier and the later versions. Documents that were not of type article were removed (e.g., editorial, review, erratum). The citations to each article were recorded. False matches were removed (e.g., International Journal of Information Processing and Management), as were matches before 1996 and after 2013. Before 1996 the article lists for JASIST (then called Journal of the American Society for Information Science) had large gaps, for example with only two articles from 1995 (this coincides with a change in Scopus coverage: Li, Burnham, Lemley, \& Britton, 2010) and hence it made sense to start at 1996. Searches for some of the missing pre-1996 article titles confirmed that they were not in Scopus.

All articles 1996-2013 in the four journals (IPM: 1117; JASIST: 2315; JDoc: 523; LISR: 434) were searched for by title in quotes (after removing all non-alphanumeric characters, such as colons, except for apostrophes), first author last name and publication year through the Mendeley API via the free software Webometric Analyst. For example, the query for one article [Rosemblat, G., Resnick, M. P., Auston, I., Shin, D., Sneiderman, C., Fizsman, M., \& Rindflesch, T. C. (2013). Extending SemRep to the public health domain. Journal of the American Society for Information Science and Technology, 64(10), 1963-1974.] was: title:"Extending SemRep to the public health domain" AND author:Rosemblat AND year:2013 
In some cases there were multiple matches, mainly due to the same article being entered in a slightly different format by different Mendeley users. When this occurred the record with the most readers was retained. It would also have been possible to total the readers for all matching records and this would have slightly increased the results, but a cautious approach was taken instead because some of the matches may have been for other versions of a paper (e.g., a related conference presentation), although this only happened 18 times. In total, 76197 readers were found and 2662 (3\%) were excluded for being for duplicate records and so this would not affect the results much. A manual check of all matching titles found 15 additional cases where an incorrect article matched the results but this accounted for only 241 readers so this would not affect the results. A check of a random sample of 100 of the remaining articles found no cases where Mendeley had matched an incorrect article. This manual verification used the title and journal name, as recorded in Mendeley, and compared it to the title and journal searched for.

In cases where no matches were found, the following explanations are theoretically possible.

- There were no Mendeley readers of the article.

- Mendeley readers of the article had incorrectly entered its title, first author last name, or year.

- Scopus had an incorrect version of the article title, first author last name, or year.

- The Mendeley query did not match the article because of the search matching process in Mendeley - for example unusual characters in the article title or very long titles.

The last of the above is potentially the most worrying because it suggests a systematic rather than a random bias. It did not seem to be a common problem because Mendeley found matches for long complex titles, such as "Seeking information for a middle school history project: The concept of implicit knowledge in the students' transition from Kuhlthau's Stage 3 to Stage 4", containing words, digits, a colon and two apostrophes. Search matching is likely to be a more significant problem in subject areas in which chemical or mathematical formulae are common in titles.

\section{Results}

Figures 1 to 4 report the median number of readers and citers for articles from the four journals for articles published in each year. Lower and upper quartiles are also reported to give an indication of trends for higher and lower impact articles as well as for the average impact articles. The median is used rather than the mean because citation data is typically skewed (de Solla Price, 1976) and means can therefore be misleading. The graphs are all jagged rather than smooth but these may be natural variations due to the small numbers of articles published in each year, especially in the early years when journal issues were smaller. The points in time at which citations start to exceed readers are of interest because the discriminatory power of any metric depends in part on the amount of data available. These points in time can be summarised as follows.

- IPM: Lower quartile: 2007; Median: 2007; Upper quartile: 2007.

- JASIST: Lower quartile: 2003-10; Median: 2006-7; Upper quartile: 2006-7.

- JDoc: Lower quartile: 2007-10; Median: 2007; Upper quartile: 2002-5.

- LISR: Lower quartile: 2001-3; Median: 2001-4; Upper quartile: 2004-6. 


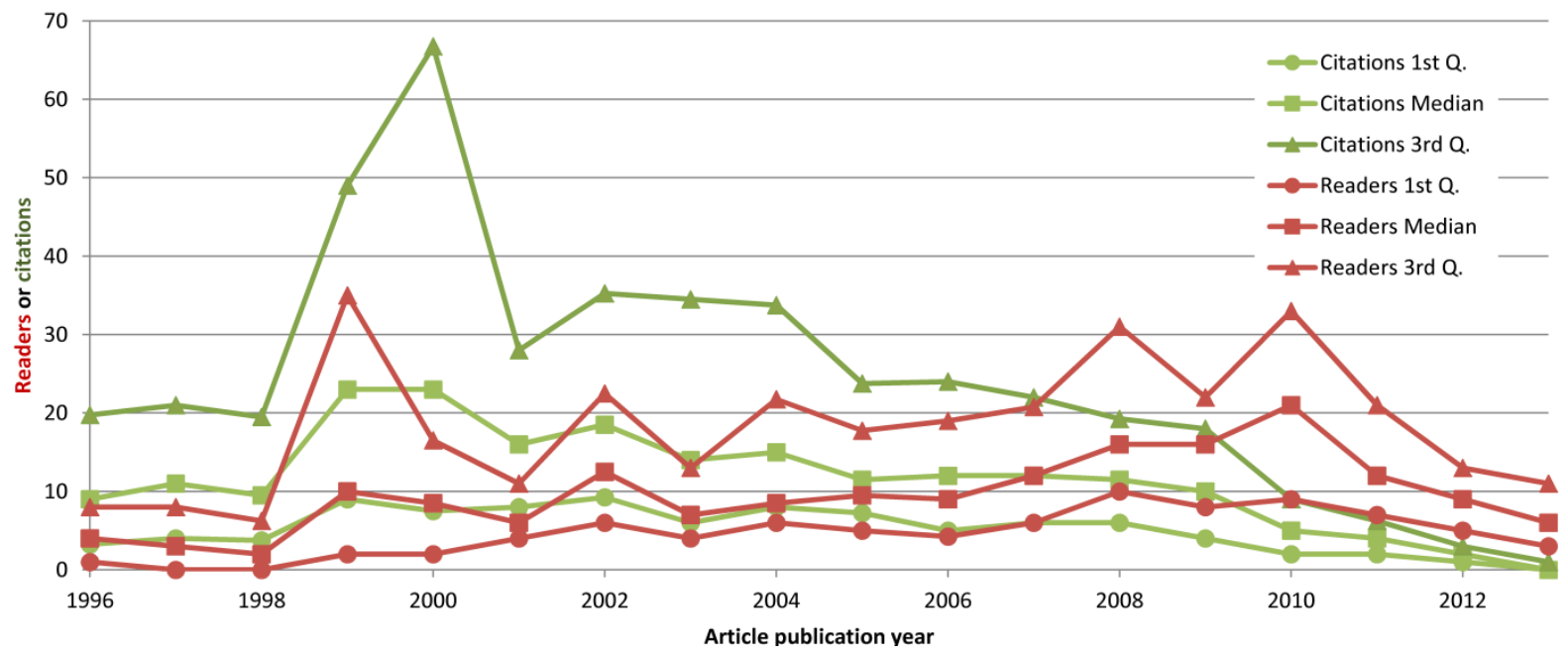

Fig. 1. Mendeley readers and Scopus citations to IPM articles 1996-2013, as recorded April 6, 2014.

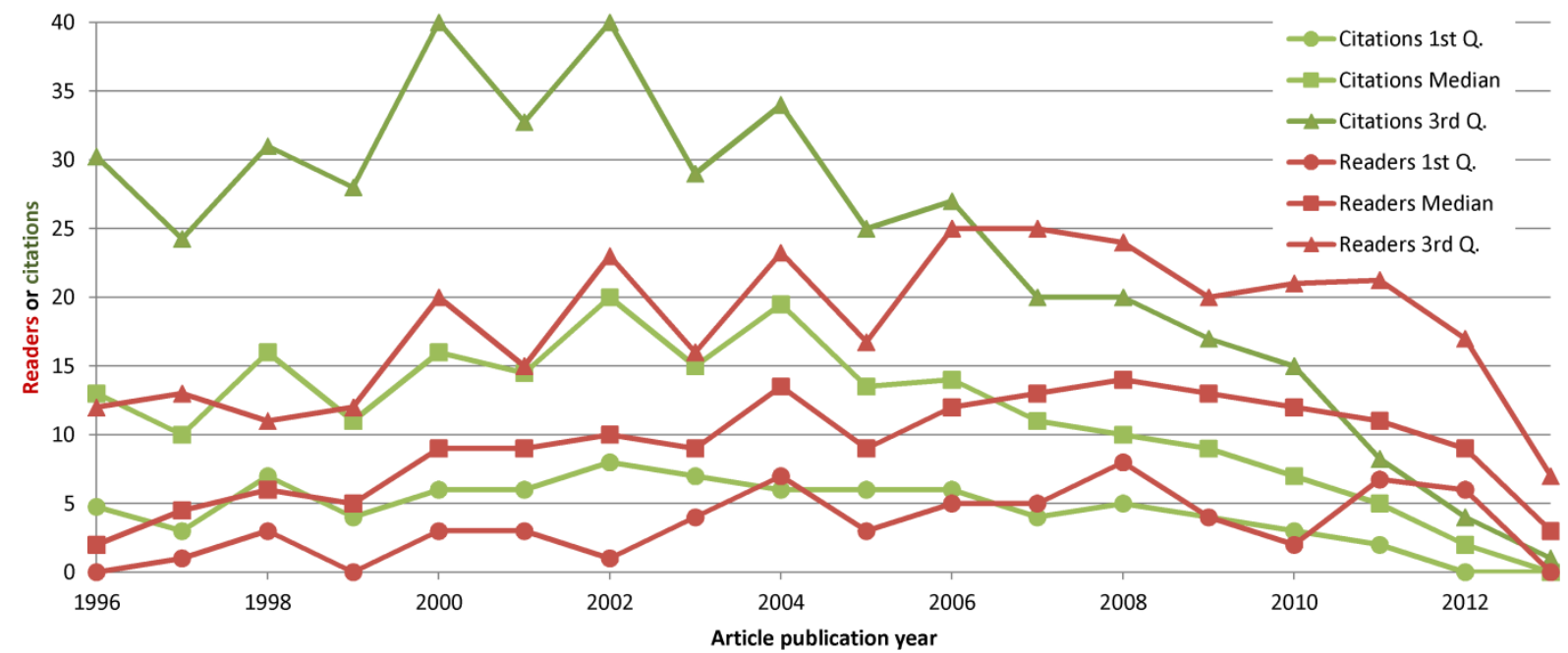

Fig. 2. Mendeley readers and Scopus citations to JASIST articles 1996-2013, as recorded April 6, 2014.

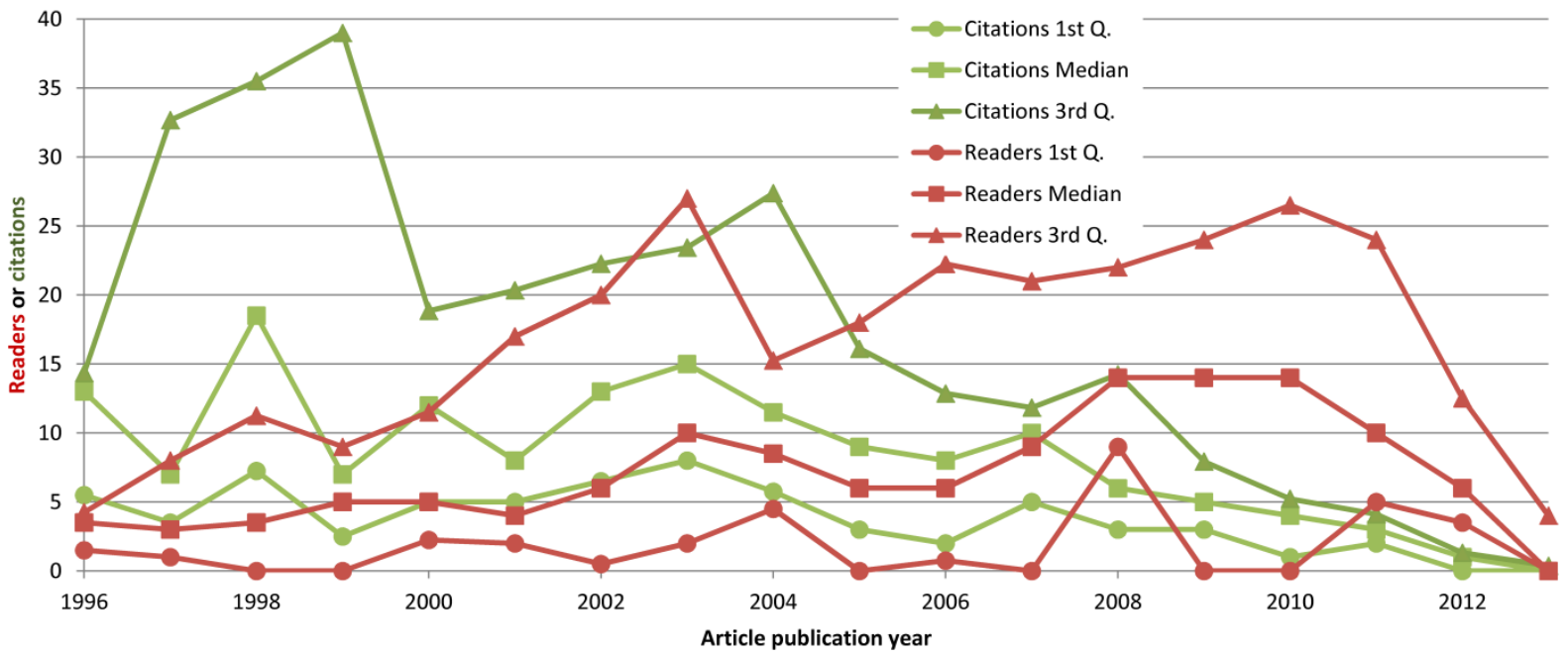

Fig. 3. Mendeley readers and Scopus citations to JDoc articles 1996-2013, as recorded April 6, 2014. 


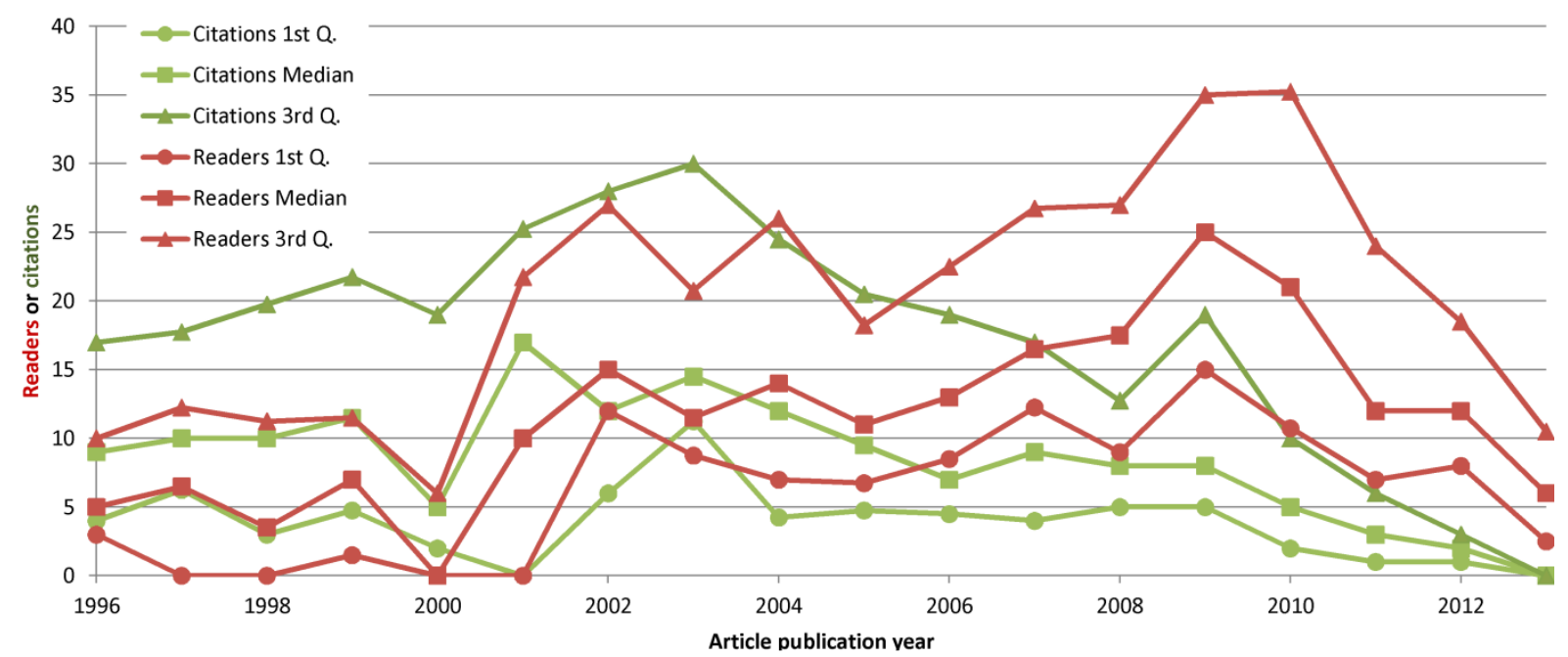

Fig. 4. Mendeley readers and Scopus citations to LISR articles 1996-2013, as recorded April 6, 2014.

Although statistical power, and hence the amount of data, is important, correlation tests are useful to assess whether a new metric, such as Mendeley readers, is related to an established metric, such as citations. Figure 5 shows the Spearman correlations between the two metrics, calculated separately for each year but combined for all journals due to the low numbers involved. All correlations are significantly positive and the correlation seems to increase annually from 2003 until about 2006, after which it stays approximately constant at around 0.6. The lower early correlation is an expected by-product of the lower numbers for both readers and citations, since lower numbers reduce the statistical power of the correlation tests. The stabilisation of the correlation for all years before 2006 runs counter to this to some extent since the median number of readers is relatively low for 1996 and a few years after. It is possible that older articles are more likely to be ignored if they are not highly cited so that readership for old articles would be influenced by citation patterns.

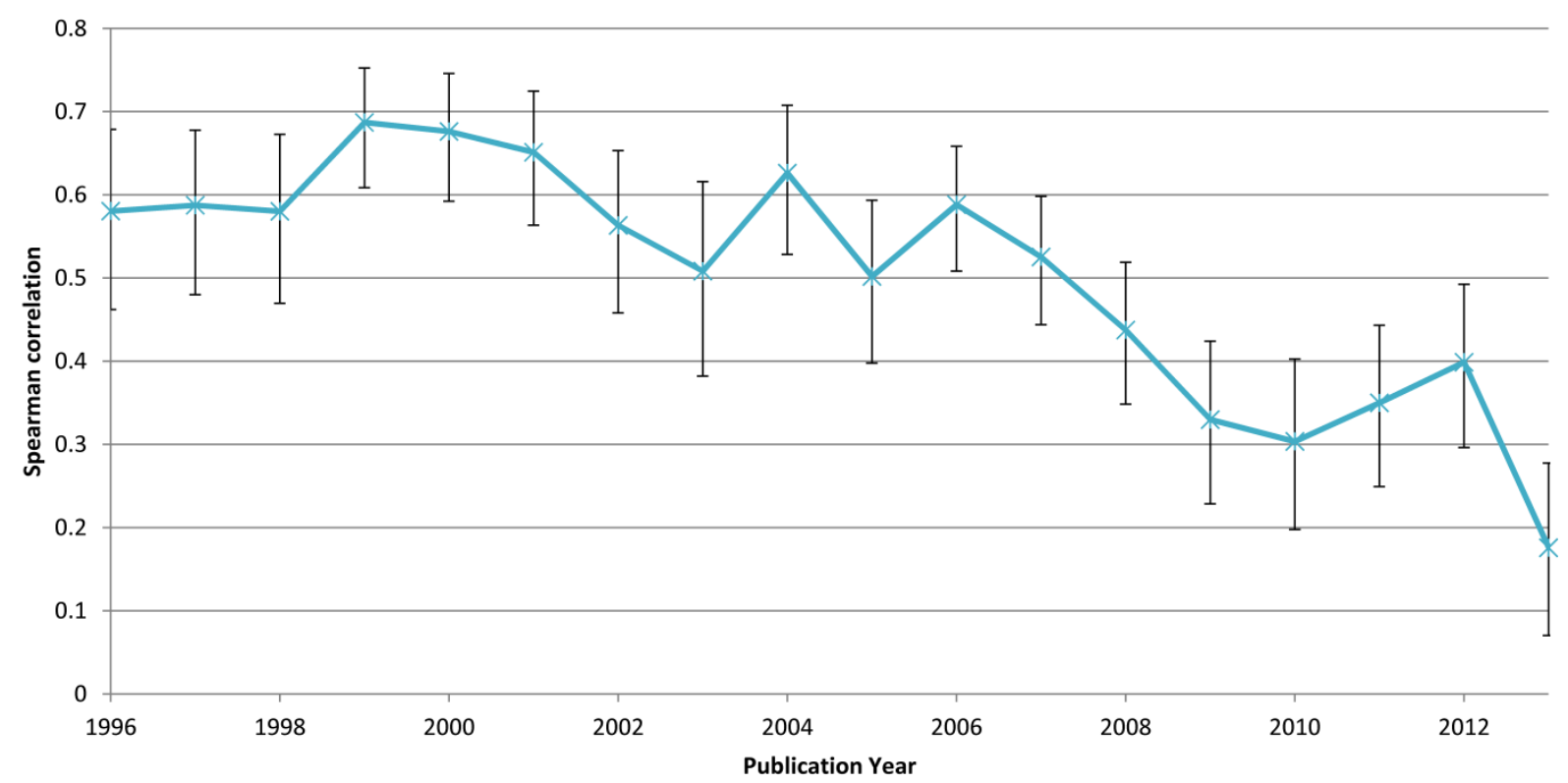

Fig. 5. Spearman correlations between Mendeley readers and Scopus citations to articles 1996-2013 from IPM, JASIST, JDoc, and LISR, as recorded April 6, 2014. Error bars represent 95\% confidence intervals. 


\section{Limitations}

An important limitation of the empirical part of these findings is that the temporal patterns will be different for disciplines in which Mendeley usage is much higher or much lower than in LIS and the same is true for citations. The temporal patterns may also change if Mendeley becomes more popular or less popular in the future. All other factors being equal, the number of readers for older Mendeley articles will increase as new users enter the system, assuming that the older users do not delete their accounts, and so the time taken for citation counts to catch up with reader counts should tend to increase by just under a year per year. This is based on the assumption that Mendeley readership counts for articles decrease in figures 1-4 for older articles because less articles are registered before the service began. In five years' time, for example, the decrease will presumably still occur in about 2008, giving an extra five years of Mendeley readership increases. Finally, there are probably many other journals that, like LISR, have relatively many readers compared to citers (e.g., perhaps the Journal of Education for Library and Information Science) or vice versa, and hence their results could be substantially different.

\section{Conclusions}

The results suggest that LIS articles tend to attract more Mendeley readers than citations initially, but that the situation reverses after about 7 years. This period of time will probably lengthen in the future if the number of Mendeley users stays constant or increases. Although readership and citation are not comparable, this finding confirms that Mendeley readership figures are substantial in LIS and may be more useful than citations for indicating the likely future impact of recent articles. For example, Mendeley readers are at least numerically comparable to Scopus citations for the past 7 years and are not substantially smaller for the past decade. Hence Mendeley readership has the potential to be valuable as an impact indicator for LIS articles that are up to a decade old, albeit not for the same type of academic impact as that indicated by citations. Moreover, the high and apparently stable correlation between Mendeley readership and citations for another ten years suggests that Mendeley readership figures may also be useful impact indicators in the long term. Nevertheless, the theoretical discussion of factors affecting Mendeley readership rates shows that figures should not be compared between years unless normalised against articles from the same year. Even comparing readership counts between articles from the same year is unfair to articles published late in the year, as it is for citations (Levitt \& Thelwall, 2011), but this issue is likely to be particularly important when comparing recent articles.

Mendeley readership statistics should not be taken at face value as the number of readers of an article. An unknown proportion of article readers register the article in Mendeley, and this proportion probably varies by discipline and year. Some articles may also be registered by people that haven't read them, such as journal publishers and librarians compiling article lists and those who intend to read an article but do not get round to it or decide that it is not relevant or who just read the abstract. Some authors may register their own articles in Mendeley although presumably most authors have read their own articles. As discussed in the methods section above, there are also practical limitations which mean that Mendeley readership counts may not always be correctly obtained from Mendeley.

It is not meaningful to directly compare readers and citers because a citation implies both reading the article (although not necessarily recording it in Mendeley) and finding it 
useful enough to incorporate into future research. Hence individual citations are, in general, more valuable than individual readers, although there are exceptions, such as perfunctory citations. Nevertheless, the situation is more complex because if Mendeley reader statistics are taken as indicators of the wider readership of an article (e.g., representing $10 \%$ of the actual readerships - for example under $10 \%$ of European highly cited academics have Mendeley profiles: Mas-Bleda, Thelwall, Kousha, \& Aguillo, in press) then it is not clear that, say, 10 Mendeley readers indicates less overall impact than 10 Scopus citations (of course, many citations are not captured in Scopus too). In this context, a decision about the relative values of readership and citation to society (i.e., exchange rates: Wouters, \& Costas, 2014) would be needed in order to decide on the relative values of Mendeley readership statistics and citation counts and this would have to include a consideration of the different types of impacts reflected in both.

\section{References}

Abrizah, A., Zainab, A. N., Kiran, K., \& Raj, R. G. (2013). LIS journals scientific impact and subject categorization: a comparison between Web of Science and Scopus. Scientometrics, 94(2), 721-740.

ACUMEN (2014). Guidelines for good evaluation practice with the ACUMEN Portfolio. Available: http://research-acumen.eu/wp-content/uploads/Guidelines-Portfolio-TOCdocument.v13dx.pdf

Adie, E., \& Roe, W. (2013). Altmetric: enriching scholarly content with article-level discussion and metrics. Learned Publishing 26(1), 11-17.

Allen, H. G., Stanton, T. R., Di Pietro, F., \& Moseley, G. L. (2013). Social media release increases dissemination of original articles in the clinical pain sciences. PlOS ONE, 8(7), e68914.

Alperin, J. P. (2013). Ask not what altmetrics can do for you, but what altmetrics can do for developing countries. Bulletin of the American Society for Information Science and Technology, 39(4), 18-21.

Amin, M., \& Mabe, M. (2000). Impact factors: use and abuse. Perspectives in Publishing, $1(2), 1-6$.

Bar-Ilan, J., Haustein, S., Peters, I., Priem, J., Shema, H., \& Terliesner, J. (2012). Beyond citations: Scholars' visibility on the social Web. In Proceedings of 17th International Conference on Science and Technology Indicators (pp. 98-109), Montréal: ScienceMetrix and OST.

Barr, D. (2006). Staying alert: The wild new world of current awareness services. College \& Research Libraries News, 67(1), 14-17.

Beall, J. (2012). Article-level metrics: An ill-conceived and meretricious idea. Available: http://scholarlyoa.com/2013/08/01/article-level-metrics/

Björk, B. C., \& Solomon, D. (2013). The publishing delay in scholarly peer-reviewed journals. Journal of Informetrics, 7(4), 914-923.

Breese, J. S., Heckerman, D., \& Kadie, C. (1998). Empirical analysis of predictive algorithms for collaborative filtering. In Proceedings of the Fourteenth conference on Uncertainty in artificial intelligence (pp. 43-52). Morgan Kaufmann Publishers Inc..

Brewerton, G. (2014). Implications of Student and Lecturer Qualitative Views on Reading Lists: A Case Study at Loughborough University, UK. New Review of Academic Librarianship, 20(1), 78-90, 
Case, D. O., \& Higgins, G. M. (2000). How can we investigate citation behavior? A study of reasons for citing literature in communication. Journal of the American Society for Information Science, 51(7), 635-645.

Colquhoun, D. \& Plested, A. (2014). Scientists don't count: why you should ignore altmetrics and other bibliometric nightmares. Available: http://www.dcscience.net/?p=6369

Costas, R., Zahedi, Z., \& Wouters, P. (2014). Do altmetrics correlate with citations? Extensive comparison of altmetric indicators with citations from a multidisciplinary perspective. arXiv preprint arXiv:1401.4321.

de Solla Price, D. (1976). A general theory of bibliometric and other cumulative advantage processes. Journal of the American Society for Information Science, 27(5), 292-306.

Erfanmanesh, M. A., \& Didegah, F. (2013). A Comparison of Web of Science and Scopus for Iranian Publications and Citation Impact. International Journal of Information Science \& Management, 11(1), 11-27.

Eysenbach, G. (2011). Can tweets predict citations? Metrics of social impact based on Twitter and correlation with traditional metrics of scientific impact. Journal of Medical Internet Research, 13(4), e123.

Haustein, S., Peters, I., Sugimoto, C. R., Thelwall, M., \& Larivière, V. (2014). Tweeting biomedicine: An analysis of tweets and citations in the biomedical literature. Journal of the Association for Information Science and Technology. 65(4), 656-669.

Haustein, S., Peters, I., Bar-llan, J., Priem, J., Shema, H., \& Terliesner, J. (in press). Coverage and adoption of altmetrics sources in the bibliometric community. Scientometrics.

Holmberg, K., \& Thelwall, M. (in press). Disciplinary differences in Twitter scholarly communication. Scientometrics.

Levitt, J., \& Thelwall, M. (2011). A combined bibliometric indicator to predict article impact. Information Processing \& Management, 47(2), 300-308.

Li, J., Burnham, J. F., Lemley, T., \& Britton, R. M. (2010). Citation Analysis: Comparison of Web of Science, Scopus, SciFinder, and Google Scholar. Journal of Electronic Resources in Medical Libraries, 7(3), 196-217.

Li, X., Thelwall, M., \& Giustini, D. (2012). Validating online reference managers for scholarly impact measurement. Scientometrics, 91(2), 461-471.

Lin, J., \& Fenner, M. (2013). Altmetrics in evolution: defining \& redefining the ontology of article-level metrics. Information Standards Quarterly, 25(2), 20.

Line, M. B., \& Sandison, A. (1974). Progress in documentation: 'Obsolescence'and changes in the use of literature with time. Journal of Documentation, 30(3), 283-350.

Mas-Bleda, A., Thelwall, M., Kousha, K. \& Aguillo, I.F. (in press). Do highly cited researchers successfully use the Social Web? Scientometrics.

Minasny, B., Hartemink, A. E., McBratney, A., \& Jang, H. J. (2013). Citations and the $h$ index of soil researchers and journals in the Web of Science, Scopus, and Google Scholar. PeerJ, 1, e183.

Mohammadi, E., Thelwall, M., Haustein, S., \& Larivière, V. (in press). Who reads research articles? An altmetrics analysis of Mendeley user categories. Journal of the Association for Information Science and Technology.

Mohammadi, E., \& Thelwall, M. (in press). Mendeley readership altmetrics for the social sciences and humanities: Research evaluation and knowledge flows. Journal of the Association for Information Science and Technology.

Niu, X., Hemminger, B. M., Lown, C., Adams, S., Brown, C., Level, A., McLure, M., Powers, A., Tennant, M. \& Cataldo, T. (2010). National study of information seeking behavior of 
academic researchers in the United States. Journal of the American Society for Information Science and Technology, 61(5), 869-890.

Palmer, J. (1991). Scientists and information: Using cluster analysis to identify information style. Journal of Documentation, 47(2), 105-129.

Pautasso, M. (2013). Ten Simple Rules for Writing a Literature Review. PLoS Computational Biology, 9(7), e1003149.

Peters, I., Beutelspacher, L., Maghferat, P., \& Terliesner, J. (2012). Scientific bloggers under the altmetric microscope. Proceedings of the American Society for Information Science and Technology, 49, http://www.asis.org/asist2012/proceedings/Submissions/305.pdf.

Piwowar, H., \& Priem, J. (2013). The Power of Altmetrics on a CV. Bulletin of the American Society for Information Science and Technology, 39(4), 10-13.

Priem, J., Taraborelli, D., Groth, P., \& Neylon, C. (2010). Altmetrics: A manifesto. http://altmetrics.org/manifesto/

Priem, J., \& Costello, K. L. (2010). How and why scholars cite on Twitter. Proceedings of the American Society for Information Science and Technology, 47(1), 1-4.

Roemer, R. C., \& Borchardt, R. (2013). Institutional altmetrics and academic libraries. Information Standards Quarterly, 25, 14-19.

Shema, H., Bar-Ilan, J., \& Thelwall, M. (in press). Do blog citations correlate with a higher number of future citations? Research blogs as a potential source for alternative metrics. Journal of the Association for Information Science and Technology.

Shuai, X., Pepe, A., \& Bollen, J. (2012). How the scientific community reacts to newly submitted preprints: Article downloads, twitter mentions, and citations. PloS ONE, 7(11), e47523.

Stokes, P., \& Martin, L. (2008). Reading lists: a study of tutor and student perceptions, expectations and realities. Studies in Higher Education, 33(2), 113-125.

Sud, P. \& Thelwall, M. (2014). Evaluating altmetrics. Scientometrics, 98(2), 1131-1143.

Sulaiman, M., Ahmad, N. N. N., \& Alwi, N. M. (2005). Is standard costing obsolete? Empirical evidence from Malaysia. Managerial Auditing Journal, 20(2), 109-124.

Talja, S., Vakkari, P., Fry, J., \& Wouters, P. (2007). Impact of research cultures on the use of digital library resources. Journal of the American Society for Information Science and Technology, 58(11), 1674-1685.

Tenopir, C., King, D. W., Edwards, S., \& Wu, L. (2009). Electronic journals and changes in scholarly article seeking and reading patterns. Aslib Proceedings, 61(1), 5-32.

Tenopir, C., Volentine, R., \& King, D. W. (2012). Article and book reading patterns of scholars: findings for publishers. Learned Publishing, 25(4), 279-291.

Thelwall, M., Haustein, S., Larivière, V. \& Sugimoto, C. (2013). Do altmetrics work? Twitter and ten other candidates. PLOS ONE, 8(5), e64841. doi:10.1371/journal.pone.0064841

Thelwall, M. \& Maflahi, N. (in press). Are scholarly articles disproportionately read in their own country? An analysis of Mendeley readers. Journal of the Association for Information Science and Technology.

Thelwall, M., Tsou, A., Weingart, S., Holmberg, K., \& Haustein, S. (2013). Tweeting links to academic articles. Cybermetrics: International Journal of Scientometrics, Informetrics and Bibliometrics, 17(1), paper 1.

Vakkari, P., \& Talja, S. (2006). Searching for electronic journal articles to support academic tasks. A case study of the use of the Finnish National Electronic Library (FinELib). Information Research, 12(1), http://www.informationr.net/ir/12-1/paper285.html.

Van Raan, A. F. (2004). Sleeping beauties in science. Scientometrics, 59(3), 467-472. 
Waltman, L., \& Costas, R. (2013). F1000 recommendations as a new data source for research evaluation: A comparison with citations. arXiv preprint arXiv:1303.3875.

Weller, K., Dröge, E., \& Puschmann, C. (2011). Citation analysis in Twitter: Approaches for defining and measuring information flows within tweets during scientific conferences. In Proceedings of Making Sense of Microposts Workshop (\# MSM2011).

Wouters, P. \& Costas, R. (2014). Users, narcissism and control - tracking the impact of scholarly publications in the 21 st century. Available: http://research-acumen.eu/wpcontent/uploads/Users-narcissism-and-control.pdf

Zahedi, Z., Costas, R., \& Wouters, P. (in press). How well developed are Altmetrics? Crossdisciplinary analysis of the presence of "alternative metrics" in scientific publications. Scientometrics.

Zahedi, Z., Costas, R., \& Wouters, P. (2013). What is the impact of the publications read by the different Mendeley users? Could they help to identify alternative types of impact? Available: https://openaccess.leidenuniv.nl/handle/1887/23579 (abstract) and https://www.academia.edu/6670997/What is the impact of the publications read by the different Mendeley users Could they help to identify alternative types of impact (slides) 